\title{
Inhibition of endothelial cell chemotaxis toward FGF-2 by gefitinib associates with downregulation of Fes activity
}

\author{
SHIGERU KANDA ${ }^{1,3}$, ALEXANDRA NABA ${ }^{4}$ and YASUYOSHI MIYATA ${ }^{2}$ \\ ${ }^{1}$ Department of Molecular Microbiology and Immunology, Division of Endothelial Cell Biology, and \\ ${ }^{2}$ Department of Nephrourology, Nagasaki University Graduate School of Biomedical Sciences, \\ 1-7-1 Sakamoto, Nagasaki 852-8501; ${ }^{3}$ Department of Experimental and Clinical Laboratory Medicine, \\ National Hospital Organization, Nagasaki Hospital, 41-6 Sakuragi-machi, Nagasaki 850-8523, Japan; \\ ${ }^{4}$ Morphogenèse et Signalisation Cellulaires, UMR 144 CNRS/Institut Curie, Paris, France
}

Received August 5, 2009; Accepted September 18, 2009

DOI: 10.3892/ijo_00000448

\begin{abstract}
Gefitinib inhibits epidermal growth factor-independent angiogenesis, but the molecular mechanism underlying this inhibition has yet to be defined. Here we show that gefitinib dose-dependently inhibited chemotaxis of endothelial cells toward fibroblast growth factor-2 (FGF-2), but not toward vascular endothelial growth factor-A (VEGF-A). Gefitinib inhibited lamellipodium formation by endothelial cells induced by FGF-2, but not by VEGF-A. Gefitinib at $10 \mu \mathrm{M}$ did not inhibit autophosphorylation of FGF receptor 1 or VEGF receptor 2. A non-receptor protein tyrosine kinase, Fes, has two coiled-coil domains (CCDs) in its $\mathrm{N}$-terminal region. Fes is activated by trans-autophosphorylation through CCD functions. An inactivating mutation in the second CCD abolished FGF-2 activation of Fes, indicating involvement of this CCD in FGF-2-induced Fes activation. Gefitinib-treatment decreased both CCD-independent and FGF-2- or VEGF-Apromoted Fes activity with a maximal decrease at $1 \mu \mathrm{M}$. The same results were observed in cells stably expressing kinase-inactive Fes; a dominant negative effect was observed in cells treated with FGF-2, but not with VEGF-A. Taken together, these results indicate that FGF-2 activates Fes via the second CCD, leading to lamellipodium formation and chemotaxis by endothelial cells, and gefitinib may act through Fes as an inhibitor of FGF-2-driven angiogenesis.
\end{abstract}

\section{Introduction}

A prerequisite for tumor progression and metastasis is angiogenesis, a new vascular sprout from pre-existing blood vessels, along with vascular co-option and vasculogenesis promoted

Correspondence to: Dr Shigeru Kanda, Department of Experimental and Clinical Laboratory Medicine, National Hospital Organization, Nagasaki Hospital, 41-6 Sakuragi-machi, Nagasaki 850-8523, Japan E-mail: skanda-jua@umin.net

Key words: gefitinib, Fes, FGF-2, chemotaxis, endothelial cells by circulating or bone marrow-derived endothelial progenitor/ precursor cells (1-4). Key players in angiogenesis are vascular endothelial cells, and their proliferation, migration, survival, and differentiation are essential for this process. In these biological responses, vascular endothelial growth factor (VEGF)-A plays central roles $(5,6)$, and targeting VEGF-A signaling has been extensively applied for the treatment of advanced human cancers. However, many clinical trials have shown that targeting VEGF-A signaling was effective only for a limited period followed by resistance to this therapeutic strategy $(7,8)$. One of the mechanisms underlying this resistance is a switch from VEGF-A-dependent angiogenesis to angiogenesis dependent on other proangiogenic factors, such as fibroblast growth factor (FGF)-2 (9). In recent years, the significance of FGF-2 in tumor angiogenesis has been widely recognized (10-14). Thus, for the eradication of VEGF-Aindependent tumors, targeting FGF-2 signaling may become the potential second-line therapeutic strategy for anti-angiogenesis. Because stromal-derived factor (SDF)- $1 \alpha$ and angiopoietin 2 (Ang2) may also substitute for VEGF-A-dependent angiogenesis during therapy (15-17), inhibition of intracellular signaling pathways commonly acting downstream of receptors for FGF-2, SDF-1 $\alpha$, and Ang2 would be a favorable strategy as a potential anti-angiogenic therapy.

Fes (also known as Fps) and Fer define a unique subfamily of non-receptor protein tyrosine kinases and Fes is exclusively expressed in the monocytic lineage of hematopoietic cells, vascular endothelial cells, some neuronal cell types and epithelial cells (reviewed in refs. 18-20). Fes has a unique $\mathrm{N}$-terminal region, containing two coiled-coil domains (CCDs). One of the CCD functions is inter- or intra-molecular association; however, the role of CCDs in signal transduction pathways upstream or downstream of Fes is largely unknown. Fes is activated by autophosphorylation at tyrosine 713 through functional N-terminal CCDs $(21,22)$. Using mutant Fes harboring point mutations that disrupt the coiled-coil function has revealed involvement of the first CCD in tight suppression of basal kinase activity and of the second CCD in a positive regulatory role in Rat 1 fibroblasts and TF-1 myeloid leukemia cells (23). We have previously shown that kinase activity of Fes was required for chemotaxis toward 
FGF-2 by a cultured murine brain capillary endothelial cell line, denoted IBE cells (24). IBE cells expressed endogenous Fes, and FGF-2 activated wild-type (wt) Fes in IBE cells. Stable expression of kinase-inactive Fes inhibited this FGF-2induced Fes activation, suggesting that expression of kinaseinactive Fes exerts a dominant-negative effect on endogenous Fes. Fes kinase activity was also required for Ang2-directed chemotaxis and SDF-1 $\alpha$-induced morphological differentiation of IBE cells (25-27), suggesting that Fes may be involved in angiogenesis driven by Ang 2 or SDF- $1 \alpha$.

Recent findings have indicated that FGF/FGF receptor (FGFR) signaling seems to contribute significantly to the progression of non-small cell lung cancer (NSCLC) (28-30). Because gefitinib efficiently inhibit the progression of NSCLC tumors in the clinical setting, it may inhibit an as-yet unidentified kinase acting downstream of FGFR in NSCLC cells. Certain lung cancer cells express Fes (31); however, whether gefitinib affects Fes tyrosine kinase activity remains unknown. Gefitinib is known to inhibit tumor angiogenesis (32,33). NSCLC cells produce FGF (28-30), and gefitinibmediated inhibition of NSCLC tumor growth in vivo may arise because of a blockade of FGF-activated Fes in tumor cells and in angiogenesis. To test this hypothesis, we examined the effect of gefitinib on FGF-2-mediated cellular responses and Fes activity in endothelial cells, and found that gefitinib decreased the Fes activity and chemotaxis toward FGF-2.

\section{Materials and methods}

Materials. Human recombinant FGF-2 and epidermal growth factor (EGF) were obtained from Roche Diagnostics (Tokyo, Japan). Human recombinant VEGF- $\mathrm{A}_{165}$ was purchased from PeproTech Inc., (Rocky Hill, NJ). Anti-Fes polyclonal antiserum (denoted Fps-QE) was kindly provided by Dr Peter A. Greer (Queen's Cancer Research Institute (Ontario, Canada). Anti-pY713 Fes antibody was described elsewhere (34). Anti-FLAG monoclonal antibody (M2) was purchased from Sigma Chemical Co. (St. Louis, MO). Anti-EGF receptor (EGFR) blocking antibody (mouse monoclonal, clone LA1) was purchased from Upstate Cell Signaling Solutions (Lake Placid, NY). Other antibodies were purchased from Santa Cruz Biotechnologies (Santa Cruz, CA). Gefitinib was kindly supplied by AstraZeneca (Cheshire, UK). It was dissolved in dimethyl sulfoxide (DMSO) at a concentration of $30 \mathrm{mM}$ as a stock solution and stored at $-80^{\circ} \mathrm{C}$. The stock solution was further diluted with DMSO and dissolved in culture medium just before use. The final concentration of DMSO was $0.1 \%$ in all cases. FuGENE 6 transfection reagent was obtained from Roche Diagnostics GmbH (Mannheim, Germany).

Cell culture. Porcine aortic endothelial (PAE) cells and cells stably expressing VEGFR2 (denoted KDR/PAE cells) were transfected with plasmid encoding either WT or kinase-inactive (K590E mutant; KE) Fes and several stable cell lines were obtained (27). Among these, in the present study, we used two stable PAE cell lines (WT-6 PAE cells and KE-12 PAE cells), and two stable KDR/PAE cell lines (WT-29 KDR/PAE cells or KE-4 KDR/PAE cells). PAE cells endogenously express FGFR1 and VEGFR1, whereas KDR/PAE cells additionally express human VEGFR2 (27). PAE cells over- expressing WT FGFR1 (35) was kindly provided by Dr Carl-Henrik Heldin (Ludwig Institute for Cancer Research, Uppsala, Sweden). They were cultured in Ham's F-12 medium containing $10 \%$ fetal bovine serum (FBS) and $1 \mu \mathrm{g} / \mathrm{ml}$ of hygromycin B as a selection antibiotics. Human umbilical vein endothelial cells (HUVECs) and their culture medium were obtained from Cambrex, Walkersville, MD, and the cells were cultured in endothelial cell basal medium-2 (EBM-2) supplemented with $2 \%$ FBS, $10 \mathrm{ng} / \mathrm{ml}$ VEGF-A, $20 \mathrm{ng} / \mathrm{ml}$ FGF-2, $10 \mathrm{ng} / \mathrm{ml}$ EGF, $10 \mathrm{ng} / \mathrm{ml}$ insulin-like growth factor-I, $50 \mu \mathrm{g} / \mathrm{ml}$ ascorbic acid, $100 \mathrm{ng} / \mathrm{ml}$ heparin, and $10 \mathrm{pM}$ dexamethasone.

Stable expression of WT and mutant Fes protein in PAE cells. The cDNAs encoding the WT human Fes with a C-terminallyFLAG-tag and those encoding mutations disrupting CCD functions were the kind gifts of Dr Thomas E. Smithgall (University of Pittsburgh School of Medicine, Pittsburgh, PA). Disruption of function of the first CCD was achieved with the L145P mutation, while disruption of the second CCD function was achieved with the L344P mutation. We also included a double mutant (L145P + L344P; 2LP) (23). The cDNAs were transfected into PAE cells using FuGENE 6. After $48 \mathrm{~h}$, resistant clones were selected for culturing in the presence of $200 \mu \mathrm{g} / \mathrm{ml}$ of G418 and the pool of resistant cells was examined for immunoprecipitation followed by immunoblotting as described below.

Chemotaxis assay. The chemotaxis assay to assess migration for PAE cells has been described elsewhere (27). Briefly, PAE cells suspended in Ham's F-12 medium containing 2\% FBS were seeded onto the upper surface of type I collagencoated membranes of Transwell inserts (diameter, $6.7 \mathrm{~mm}$; pore size, $8 \mu \mathrm{m}$ ). In the lower wells, Ham's F-12 medium containing $2 \%$ FBS with or without the indicated conditions was added and incubated for $4 \mathrm{~h}$. Cells that migrated to the lower membrane surface of the Transwell inserts were counted microscopically. FGF-2 at $20 \mathrm{ng} / \mathrm{ml}$ and VEGF-A at $50 \mathrm{ng} / \mathrm{ml}$ gave the maximal stimulation of chemotaxis by PAE cells. For chemotaxis of HUVECs, membranes of the Transwell inserts were coated with type I collagen and cells were suspended in EBM-2 containing 0.5\% FBS. In the lower wells, EBM-2 containing $0.5 \%$ FBS with or without the indicated factors was added. FGF- 2 at $20 \mathrm{ng} / \mathrm{ml}$ reproducibly gave the maximal stimulation of chemotaxis by HUVECs.

Immunoprecipitation and immunoblotting. Immunoprecipitation and immunoblotting were performed as described previously (24). In short, cells grown subconfluently were serum-starved with culture medium overnight, then stimulated or left unstimulated with $100 \mathrm{ng} / \mathrm{ml} \mathrm{FGF-2} \mathrm{for} \mathrm{indicated}$ periods. Cells were washed once with Tris-buffered saline (TBS), $\mathrm{pH} 7.5$, containing $100 \mu \mathrm{M}$ orthovanadate on ice and lysed in lysis buffer $(50 \mathrm{mM}$ Tris- $\mathrm{HCl}, \mathrm{pH} 7.5$ containing $0.15 \mathrm{M} \mathrm{NaCl}, 1 \%$ Nonidet P-40, $10 \mathrm{mM} \mathrm{NaF}, 1 \mathrm{mM}$ EDTA, $2 \mathrm{mM}$ Pefabloc ${ }^{\circledR} \mathrm{SC}, 0.02 \%$ sodium dodecyl sulfate (SDS), $1 \mu \mathrm{M}$ leupeptin, $100 \mu \mathrm{M}$ orthovanadate, and $100 \mathrm{U} / \mathrm{ml}$ aprotinin). After centrifugation to remove insoluble materials, the cell lysates were immunoprecipitated with the indicated antibodies, followed by the adsorption to Protein A- or 
A

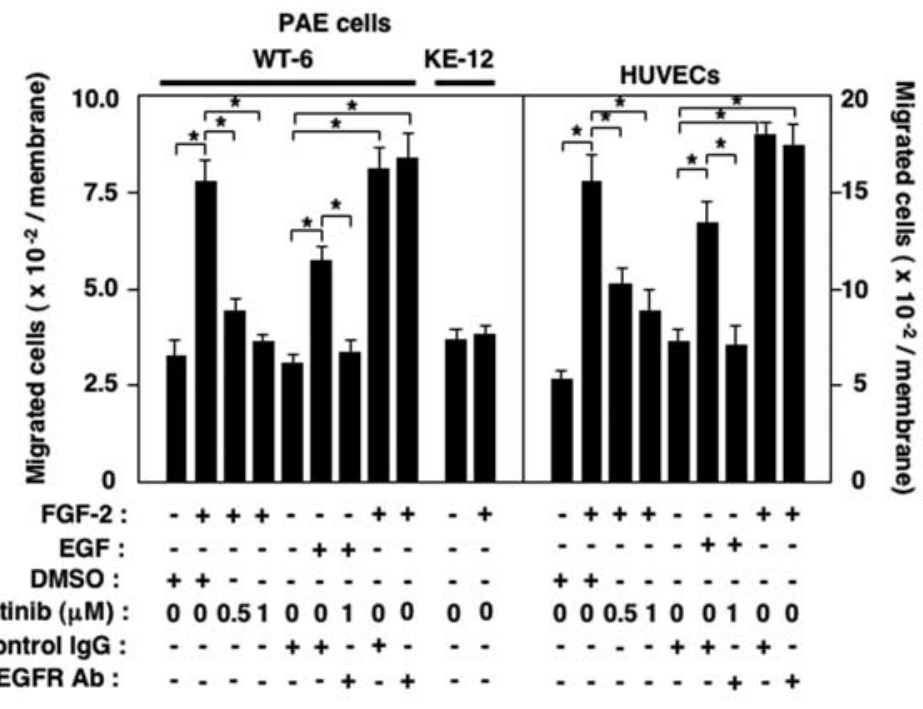

B
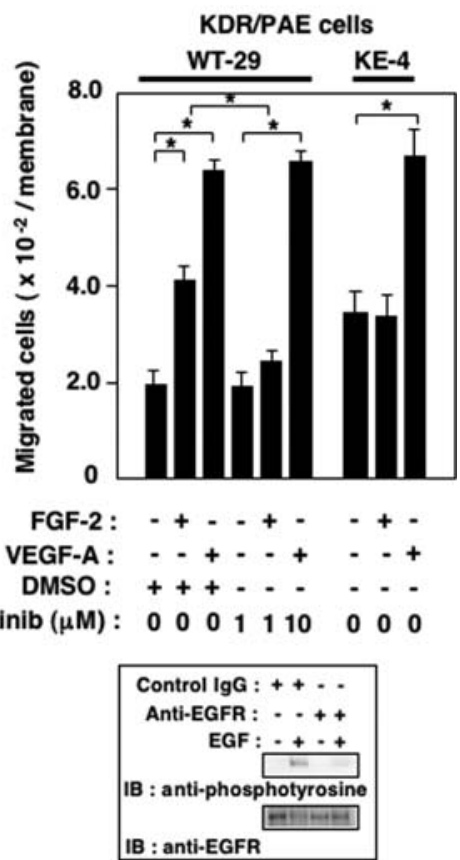

Figure 1. (A) Gefitinib inhibits chemotaxis toward FGF-2 of a PAE cell line expressing WT Fes (WT-6 cells) and HUVECs toward FGF-2, and a PAE cell line expressing kinase-inactive Fes (KE-12 cells) exhibited a dominant-negative effect on chemotaxis toward FGF-2. Culture media containing FGF-2 at 20 ng/ml or EGF at $100 \mathrm{ng} / \mathrm{ml}$ with either DMSO $(0.1 \%)$, gefitinib, control IgG $(4 \mu \mathrm{g} / \mathrm{ml})$, or anti-EGFR blocking antibody $(4 \mu \mathrm{g} / \mathrm{ml})$ were placed in the lower wells of Transwell culture plates and PAE cells or HUVECs that migrated onto the lower surface of the Transwell inserts were counted. Reproducible results were obtained from three independent experiments. (B) Gefitinib fails to inhibit chemotaxis of a KDR/PAE cell line expressing WT Fes (WT-29 cells) toward VEGF-A, and a KDR/PAE cell line expressing kinase-inactive Fes (KE-4 cells) exhibited no dominant-negative effect on chemotaxis toward VEGF-A. Culture media and counting were as described for (A) except that media contained FGF-2 at $20 \mathrm{ng} / \mathrm{ml}$ or VEGF-A at $50 \mathrm{ng} / \mathrm{ml}$ with either DMSO $(0.1 \%)$ or gefitinib at indicated concentrations. Reproducible results were obtained from three independent experiments. Inserted immonoblot shows the effect of blocking antibody against EGFR on EGF-induced phosphorylation of EGFR expressed in LLC-PK 1 cells. Cells were treated with control IgG or anti-EGF antibody for 60 min, and then stimulated or left unstimulated with $100 \mathrm{ng} / \mathrm{ml}$ EGF for $7 \mathrm{~min}$. EGFR was immunoprecipitated followed by immunoblotting. Reproducible results were obtained from two independent experiments.

Protein G-agarose beads. After the washing, proteins were eluted from beads by heating in SDS-sample buffer and then separated by SDS-polyacrylamide gel electrophoresis. After electrophoretic transfer onto polyvinylidene difluoride (PVDF) membranes (Millipore, Bedford, MA), the blots were probed with indicated antibodies. Antibody incubation was followed by incubation with horseradish peroxidase-conjugated anti-rabbit $\operatorname{IgG}$ or anti-mouse $\mathrm{IgG}$, and detection was through an enhanced chemiluminescence reaction (Thermo Scientific, Rockford, IL). Between two probings, stripping of the membrane was performed by soaking in $62.5 \mathrm{mM}$ Tris- $\mathrm{HCl}, \mathrm{pH} 6.8$, containing $2 \%$ SDS and $0.7 \% 2$-mercaptoethanol at $50^{\circ} \mathrm{C}$ for $30 \mathrm{~min}$. In indicated blots, total cell lysates were prepared by the incubation of cells with boiled SDS sample buffer and proteins from an equal number of cells were electrophoresed and analyzed.

Visualization of polymerized actin. Actin reorganization was examined as described previously (36). In brief, cells were grown on cover slips and incubated with medium containing $0.5 \%$ FBS for $16 \mathrm{~h}$. Cells were either stimulated with $50 \mathrm{ng} / \mathrm{ml}$ FGF-2 or VEGF-A or left unstimulated for indicated periods, and then washed with TBS. Cells were fixed with $3.7 \%$ paraformaldehyde in phosphate-buffered saline (PBS) for $20 \mathrm{~min}$ at room temperature, followed by incubation with $0.05 \%$ Triton X-100 in TBS for 3 min. Cells were washed with TBS and incubated with TRITC-conjugated phalloidin (Sigma
Chemical Co.) for $30 \mathrm{~min}$. After washing and mounting, photographs were taken under fluorescence microscopy. To quantify the number of lamellipodium $>100$ cells in each group were examined.

Statistical analysis. Values are presented as mean \pm SD. Differences between two groups were examined using the Mann-Whitney's U test. Differences were considered significant when P-value was $<0.05$.

\section{Results}

Gefitinib inhibits chemotaxis of endothelial cells toward FGF-2, but not toward VEGF-A. We have previously established the stable cell lines expressing either WT (WT-6 PAE cells and WT-29 KDR/PAE cells, respectively) or kinaseinactive Fes (KE-12 PAE cells and KE-4 KDR/PAE cells, respectively) (27). FGF-2 activated WT Fes via endogenous FGFR1 in both PAE and KDR/PAE cells, whereas VEGF-A activated WT Fes only in KDR/PAE cells (27). To examine the anti-angiogenic activity of gefitinib in vitro, we tested the effect of gefitinib on chemotaxis of these cells and HUVECs as primary endothelial cells. As shown in Fig. 1A, gefitinib inhibited the chemotaxis of WT-6 PAE cells toward EGF. Interestingly, gefitinib strongly inhibited the chemotaxis of these cells toward FGF-2. Blocking antibody against EGFR, which inhibits the tyrosine phosphorylation of porcine EGFR 
A

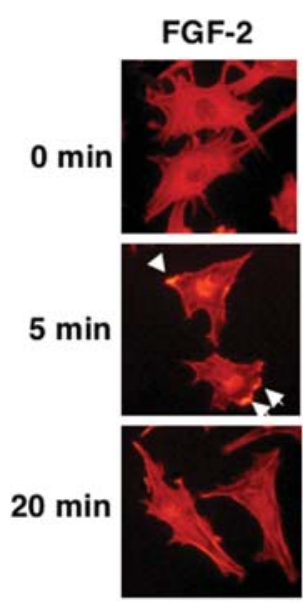

B

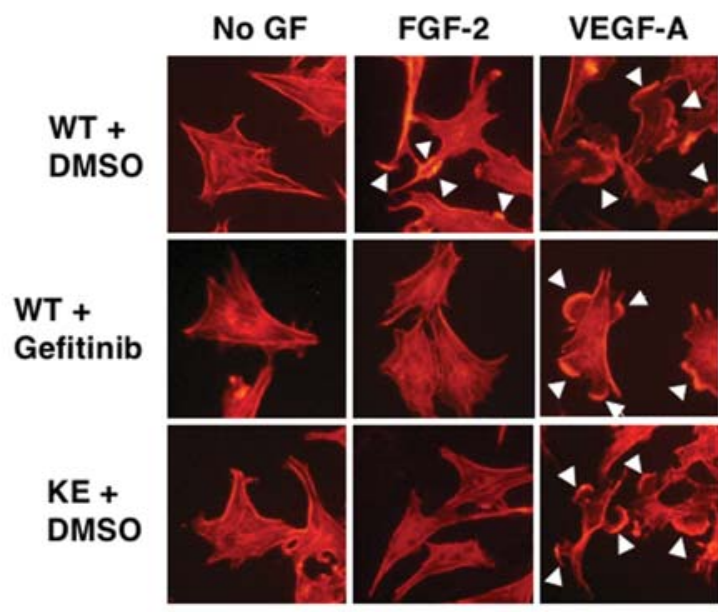

C

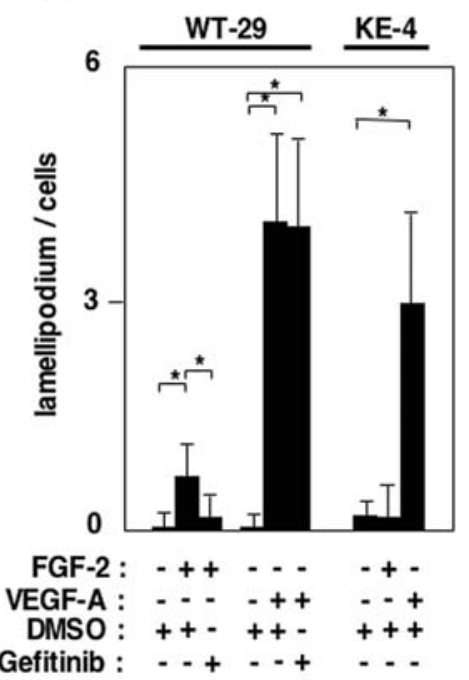

Figure 2. (A) Kinetics of FGF-2-induced actin reorganization. WT-29 KDR/PAE cells were cultured on coverslips, serum-starved for 2 h, and treated with FGF-2 $(50 \mathrm{ng} / \mathrm{ml})$ or left unstimulated for indicated periods. Cells were fixed and polymerized actin bundles were visualized with TRITC-conjugated phalloidin. White arrowhead indicates lamellipodia. Reproducible results were obtained from three independent experiments. (B) FGF-2-induced lamellipodium formation in WT-29 KDR/PAE cells (WT) is inhibited by $1 \mu \mathrm{M}$ of gefitinib or is not observed in KE-4 KDR/PAE cells (KE). Cells were cultured in the presence of either $0.1 \%$ DMSO or $1 \mu \mathrm{M}$ of gefitinib for $2 \mathrm{~h}$ and were stimulated or not for $5 \mathrm{~min}$ with FGF-2 (50 ng/ml) or VEGF-A (50 ng/ml). Cells were fixed and polymerized actin bundles were visualized with TRITC-conjugated phalloidin. White arrowhead indicates lamellipodia. Reproducible results were obtained from three independent experiments. (C) Quantification of lamellipodium formation. Number of lamellipodium in each cell was counted. In each treatment, more than 100 cells were examined.

expressed in LLC-PK1 porcine renal tubular epithelial cells (Fig. 1B insert), did not inhibit the chemotaxis toward FGF-2. This result suggested that gefitinib inhibited chemotaxis toward FGF-2 independently of signaling via EGFR. Stable expression of kinase-inactive Fes (KE-12 PAE cells) exerted a dominant-negative effect on FGF-2-directed chemotaxis, as has been observed in IBE cells (24). Gefitinib also inhibited the chemotaxis of HUVECs toward FGF-2 independently of signaling via EGFR as well. We next examined the effect of gefitinib on FGF-2- or VEGF-A-induced chemotaxis. As shown in Fig. 1B, gefitinib inhibited the chemotaxis of WT-29 KDR/PAE cells toward FGF-2, but failed to inhibit the chemotaxis toward VEGF-A even at $10 \mu \mathrm{M}$. Stable expression of kinase-inactive Fes (KE-4 KDR/PAE cells) also failed to exert a dominant-negative effect on chemotaxis toward VEGF-A. These results suggest that gefitinib inhibited chemotaxis toward FGF-2, but not toward VEGF-A, similar to the results obtained using cells expressing kinase-inactive Fes.

Gefitinib inhibits FGF-2-promoted lamellipodium formation in PAE cells. Actin reorganization is one of the critical cellular responses of cytokine-initiated cell motility. Especially, stress fiber fomation, fillopodium or lamellipodium formation are main features of actin reorganization observed during motility of a variety of cells. We first examined the kinetics of actin reorganization in FGF-2-treated WT-29 KDR/PAE cells. As shown in Fig. 2A, FGF-2 induced lamellipodium formation at $5 \mathrm{~min}$ and smaller lamellipodia were observed at $20 \mathrm{~min}$. Stress fiber formation or fillopodium formation were not remarkable during FGF-2-treatment in these cells. We then examined the effect of gefitinib on lamellipodium formation by either FGF-2 or VEGF-A at $5 \mathrm{~min}$. As shown
IP : Anti-FLAG (M2)

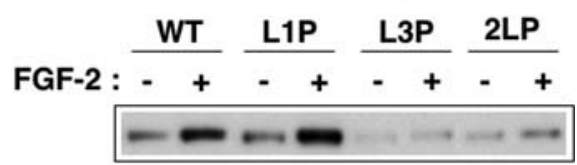

Fold phosphorylation : $\begin{array}{llllllll}1.0 & 2.8 & 4.1 & 11.3 & 1.3 & 1.4 & 2.0 & 1.9\end{array}$ IB : Anti-pY713 Fes

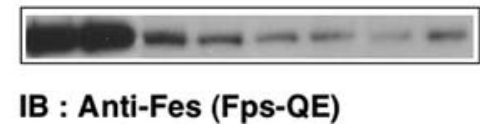

Figure 3. Mutations in the CCDs affect basal or FGF-2-induced kinase activity of Fes in PAE cells. PAE cells stably expressing FLAG-tagged WT, a first CCD mutant (L145P; denoted L1P), a second CCD mutant (L344P; denoted L3P), or the double CCD mutant (denoted 2LP) Fes were serum-starved for $2 \mathrm{~h}$ and then stimulated with FGF-2 (100 ng/ml) for $15 \mathrm{~min}$. Fes was immunoprecipitated with anti-FLAG antibody (M2), and separated by SDS-PAGE, followed by transfer onto PVDF membranes; autophosphorylation of Fes was examined by immunoblotting with the use of antiphospho-Y713 Fes antibody ( $\mathrm{pY}^{713}$ Fes). Fold phosphorylation was calculated by the ratio of an intensity of pY713 Fes/total Fes and normalized to the ratios observed with untreated WT Fes-expressing cells. Reproducible results were obtained from three independent experiments.

in Fig. 2B and C, FGF-2 induced lamellipodium formation in WT-29 cells, as did VEGF-A. Gefitinib only inhibited lamellipodium formation induced by FGF-2. In KE-4 KDR/PAE cells, FGF-2 failed to induce lamellipodium formation; however, VEGF-A did induce it in these cells. These cellular responses were closely associated with chemotaxis of PAE or KDR/PAE cells expressing kinase-inactive Fes. 
A

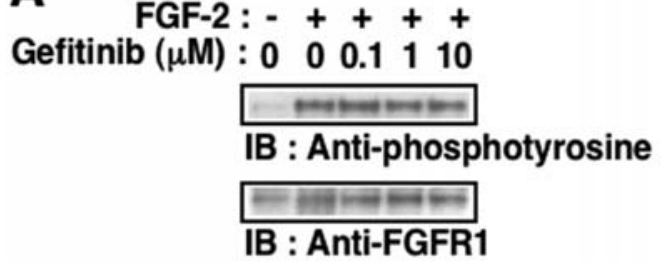

B

Gefitinib $(\mu \mathrm{M}): \begin{array}{lllll}0 & 0 & 0.1 & 1 & 10\end{array}$

IB : Anti-phosphotyrosine

IB: Anti-VEGFR2

C

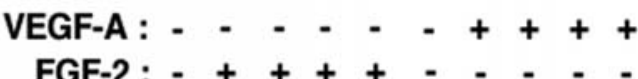

Gefitinib $(\mu \mathrm{M}): 0 \begin{array}{llllllllll}0 & 0 & 0.1 & 1 & 10 & 0 & 0 & 0.1 & 1 & 10\end{array}$

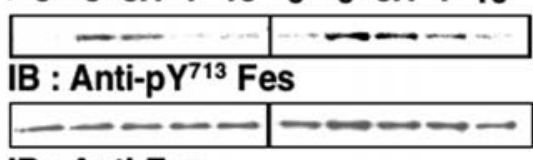

IB : Anti-Fes
D

FGF-2 : - + - +

Gefitinib $(\mu \mathrm{M}): \begin{array}{llll}0 & 0 & 1 & 1\end{array}$

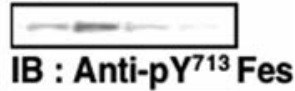

IB : Anti-Fes

E

FGF-2 : - + - +

Gefitinib $(\mu \mathrm{M}): 0 \begin{array}{llll}0 & 0 & 1 & 1\end{array}$

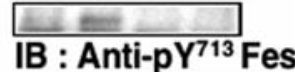

IB : Anti-Fes

$\mathbf{F}$

Gefitinib $(\mu \mathrm{M}): 00.010 .1110$

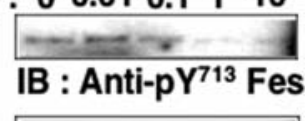

IB : Anti-Fes

Figure 4. (A) Gefitinib does not inhibit the autophosphorylation of FGFR1. PAE cells overexpressing FGFR1 were cultured in 6-cm dishes, serum-starved overnight, and further incubated with DMSO or gefitinib at indicated concentrations for $2 \mathrm{~h}$. Cells were stimulated or left unstimulated with FGF-2 at $100 \mathrm{ng} / \mathrm{ml}$ for 8 min. FGFR1 was immunoprecipitated, followed by the separation with SDS-PAGE. Autophosphorylation of FGFR1 was examined by immunoblotting. Reproducible results were obtained from two independent experiments. (B) Gefitinib does not inhibit the autophosphorylation of VEGFR2. WT-29 KDR/PAE cells were cultured in 6-cm dishes, serum-starved overnight, and further incubated with DMSO or gefitinib at indicated concentrations for 2 h. Cells were stimulated or left unstimulated with VEGF-A at $100 \mathrm{ng} / \mathrm{ml}$ for $8 \mathrm{~min}$. VEGFR2 was immunoprecipitated, followed by the separation with SDS-PAGE. Autophosphorylation of VEGFR2 was examined by immunoblotting. Reproducible results were obtained from two independent experiments. (C) Gefitinib decreases FGF-2- and VEGF-A-promoted Fes activity in KDR/PAE cells. KDR/PAE cells expressing WT Fes were serum-starved for $2 \mathrm{~h}$ and then stimulated with FGF-2 $(100 \mathrm{ng} / \mathrm{ml})$ or VEGF-A $(100 \mathrm{ng} / \mathrm{ml})$ for $15 \mathrm{~min}$. FLAG-tagged Fes was immunoprecipitated, followed by the separation with SDS-PAGE. Autophosphorylation of Fes was examined by immunoblotting with the use of anti-pY ${ }^{713}$ Fes antibody. Reproducible results were obtained from three independent experiments. (D) Gefitinib decreases FGF-2-promoted Fes activity in PAE cells. PAE cells expressing WT Fes were processed as in (C) except for being stimulated only with FGF-2 (100 ng/ml) for $15 \mathrm{~min}$. Reproducible results were obtained from two independent experiments. (E) Gefitinib decreases FGF-2-promoted Fes activity in HUVECs. HUVECs were processed as in (D). Reproducible results were obtained from two independent experiments. (F) Gefitinib decreases the kinase activity of Fes harboring the loss-of-coiled-coil mutations. PAE cells expressing Fes with double CCD mutations (L145P and L344P, denoted 2LP cells) were serum-starved for $2 \mathrm{~h}$ and then processed for blotting as in (D). Reproducible results were obtained from three independent experiments.

A point mutation in the second CCD abolishes the FGF-2mediated increase in Fes kinase activity in PAE cells. The mechanisms of how FGF-2 activates Fes are unknown. To examine the role of CCDs in the activation of Fes, we transfected the plasmid encoding FLAG-tagged WT and coiledcoil mutant Fes into PAE cells, obtaining pools of G418resistant stable cell lines. Because cell density affects intracellular signaling pathways, we always used subconfluent cultures of transfected cells in the experiments described below. We examined the activation of Fes by immunoblotting, probing with anti-pY713 Fes antibody, which recognizes the autophosphorylated Fes responsible for the kinase activation. As shown in Fig. 3, the basal kinase activity of L145P mutant Fes was $\sim 4$ times higher than that of WT Fes. FGF-2 increased the autophosphorylated WT and L145P Fes in PAE cells. By contrast, Fes harboring point mutation in the second CCD (L344P and L145P/L344P double mutations) was defective for FGF-2-induced activation. Thus, it seems likely that mutation of the first CCD is responsible for the release of basal kinase activity, and the intact second $\mathrm{CCD}$ was required for FGF-2-induced activation of Fes in PAE cells.

Gefitinib dcreases the autophosphorylation of Fes in endothelial cells. A previous report has demonstrated that gefitinib inhibited VEGFR2 kinase activity, or FGF-2- and VEGF-A-induced proliferation of HUVECs at the micromolar level (37). Expression of endogenous FGFR1 in PAE cells is extremely low and thus, it is difficult to examine the autophosphorylation of endogenous FGFR1. Therefore, to determine whether gefitinib inhibits FGFR1 tyrosine kinase activity, we studied the autophosphorylation of overexpressed FGFR1 in PAE cells. As shown in Fig. 4A, FGF-2-treatment promoted autophosphorylation of FGFR1, and gefitinib even at $10 \mu \mathrm{M}$ did not inhibit the phosphorylation. We also examined the effect of gefitinib on the autophosphorylation of VEGFR2. VEGF-A potently promoted autophosphorylation of VEGFR2 in WT-29 cells and gefitinib at $10 \mu \mathrm{M}$ showed no significant effect (Fig. 4B). These results suggest that 


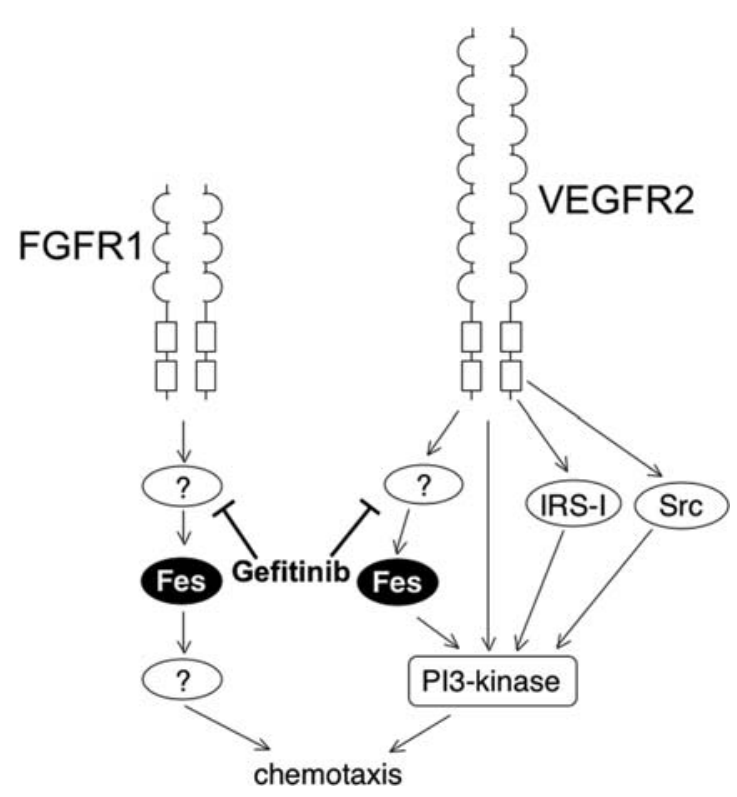

Figure 5. Proposed signal transduction pathway leading to chemotaxis toward FGF-2 or VEGF-A by PAE cells. Gefitinib inhibits certain target signaling molecule(s) upstream of Fes, resulting in the decrease in Fes kinase activity. FGF-2-activated Fes regulates chemotaxis toward FGF-2. Chemotaxis toward VEGF-A is inhibited by a PI3-kinase inhibitor, LY294002 (27). VEGF-A activates PI3-kinase through VEGFR-2 by inducing the binding of PI3-kinase to VEGFR2, insulin receptor substrate-I (IRS-I), Fes, and Src (27). Inhibition of Fes alone with gefitinib fails to inhibit VEGF-A-activated PI3kinase; thus, chemotaxis toward VEGF-A is insensitive to gefitinib-treatment.

gefitinib does not seem to inhibit FGFR1 or VEGFR2 in these cultured endothelial cells even at $10 \mu \mathrm{M}$.

We next examined the effect of gefitinib on FGF-2- or VEGF-A-induced autophosphorylation of Fes in WT-29 KDR/PAE cells. As shown in Fig. 4C, gefitinib at $1 \mu \mathrm{M}$ maximally decreased both FGF-2- and VEGF-A-treated autophosphorylation of Fes, and gefitinib at $10 \mu \mathrm{M}$ did not further decrease. We also examined the effect of gefitinib on FGF-2-induced autophosphorylation of Fes in PAE cells and HUVECs. As shown in Fig. 4D and E, gefitinib at $1 \mu \mathrm{M}$ strongly decreased the FGF-2-treated autophosphorylation of Fes in these cells. FGF-2-induced autophosphorylation of Fes is regulated by CCDs. To examine whether gefitinib decreases autophosphorylation of Fes independent of CCD function, we studied the Fes activity in gefinitib-treated or untreated 2LP cells. As shown in Fig. 4F, gefitinib at $1 \mu \mathrm{M}$ resulted in a maximal decrease in the autophosphorylation of Fes.

\section{Discussion}

Gefitinib has been appreciated as a highly specific inhibitor for Erb B family receptor tyrosine kinases, especially for Erb B1, an EGFR tyrosine kinase (38), and is widely used for the treatment of patients with advanced NSCLC. Gefitinib also can inhibit angiogenesis (32,33). Recent studies have indicated that the progression of NSCLC utilizes FGF/FGFR signaling (28-30). Therefore, gefitinib may inhibit angiogenesis promoted by NSCLC cell-derived FGF during treatment. The present study provides evidence for the first time that gefitinib can inhibit chemotaxis toward FGF-2 by endothelial cells, the critical cellular response for angiogenesis.
In endothelial cells in this study, Fes kinase activity was downregulated by treatment with gefitinib (Fig. 4C-F). However, in other work, gefitinib failed to inhibit Fes activity directly as assessed by in vitro tubulin phosphorylation assay (unpublished observation by Hellwig and Smithgall), suggesting that gefitinib indirectly inhibited Fes activity in endothelial cells. Inhibition of Fes does not seem to involve EGFR-mediated signaling, because blocking antibody against EGFR showed no effect on chemotaxis toward FGF-2 in either PAE cells or HUVECs (Fig. 1A). Screening with an immobilized compound from gefitinib identified that GAK and RICK as possible target kinases for gefitinib (39). According to the competition of binding between T7 bacteriophage-tagged kinases and immobilized gefitinib, GAK was again identified as a potential target for gefitinib $(40,41)$. A Src homology 2 (SH2) domain is required for full kinase activation (42). Association of an $\mathrm{SH} 2$ domain with autophosphorylated Fes kinase itself stabilizes the activated conformation of the kinase domain and binding of particular ligands to the SH2 domain further stabilizes the active conformation of the catalytic domain (43). Therefore, an as yet undefined protein tyrosine kinase, such as GAK, or association of the Fes SH2 domain with tyrosinephosphorylated ligands may be involved in the regulation of Fes kinase activity, and gefitinib may modulate these signaling events.

In the present study, we showed that FGF-2-induced activation of Fes seems to require the second CCD function. FGF-2-induced activation was not observed in Fes with the mutant second CCD, while FGF-2 did activate Fes with the intact second $\mathrm{CCD}$ even in the presence of the mutant first CCD (Fig. 3). We performed transfection experiments three times independently, and the expression level of WT Fes protein was always considerably higher than mutant Fes proteins in all transfection experiments (data not shown). The reason for the higher expression of WT Fes is not yet clear. One possibility is the decreased stability of the mutant Fes. Alternatively, high basal kinase activity of mutant Fes may be toxic for endothelial cells, because kinase activity of WT Fes (endogenous Fes) is tightly downregulated in endothelial cells.

Activation of class I phosphoinositide 3 (PI3)-kinase involves multiple mechanisms, including the binding of PI3-kinase to tyrosine-phosphorylated proteins, which bring PI3-kinase close to the plasma membrane (44). In VEGF-Atreated KDR/PAE cells, PI3-kinase was activated through binding to active Fes (27). VEGF-A-directed chemotaxis and VEGF-A-promoted morphological differentiation of KDR/PAE cells are dependent on PI3-kinase activation, because PI3kinase inhibitor, LY294002, inhibited these cellular responses (27). Expression of kinase-inactive Fes did not inhibit VEGF-A-activated PI3-kinase; VEGF-A activates PI3-kinase in KDR/PAE cells through multiple pathways involving the binding of PI3-kinase to VEGF receptor (VEGFR) 2, insulin receptor substrate-I, and Src, all of which can substitute for the expression of kinase-inactive Fes (27). Gefitinib-treatment did not decrease the phosphorylation of Ser473 of Akt1 promoted by VEGF-A in KDR/PAE cells (unpublished data). Thus, it seems likely that inhibition of Fes by gefitinib did not affect chemotaxis of KDR/PAE cells toward VEGF-A 
because of intact PI3-kinase activation (Fig. 5). By contrast, Fes does not activate PI3-kinase in FGF-2-treated endothelial cells (24) and LY294002 did not inhibit the chemotaxis of PAE cells toward FGF-2 (unpublished data). It seems that FGF-2-activated Fes uses different downstream signaling molecule(s) other than PI3-kinase. The effecter molecules of Fes in FGF-2-treated endothelial cells have not yet been identified.

A previous report has shown that gefitinib inhibited FGF-2or VEGF-A-induced proliferation of HUVECs at 1-3 $\mu \mathrm{M}$ and that the $\mathrm{IC}_{50}$ value of gefitinib on VEGFR2 kinase activity was 3.7-10 $\mu \mathrm{M}$ (37). In the present study, gefitinib at $10 \mu \mathrm{M}$ failed to inhibit the autophosphorylation of FGFR 1 and VEGFR2. Nevertheless, gefitinib at $1 \mu \mathrm{M}$ gave the maximal inhibition of Fes activity (Fig. 4C-F). Notably, oral administration of gefitinib in cancer patients achieves a concentration of $1 \mu \mathrm{M}$ in serum (45). Thus, gefitinib may inhibit angiogenesis via Fes during the treatment of NSCLC in humans.

\section{Acknowledgements}

We greatly appreciate Dr Thomas E. Smithgall (University of Pittsburgh School of Medicine, Pittsburgh, PA) for cDNAs encoding FLAG-tagged wild-type, L145P, L344P, or double mutant (L145P and L344P) human Fes and fruitful discussions; Dr Peter A. Greer (Queen's Cancer Research Institute, Ontario, Canada) for anti-Fes polyclonal antiserum (Fps-QE); Dr CarlHenrik Heldin (Ludwig Institute for Cancer Research, Uppsala, Sweden) for PAE cells expressing WT FGFR1; Dr Monique Arpin (Morphogenèse et Signalisation Cellulaires, UMR 144 CNRS/Institut Curie, Paris, France) and Dr Sabine Hellwig (University of Pittsburgh School of Medicine, Pittsburgh, PA) for critical reading of the manuscript; and AstraZeneca for gefitinib. We are also grateful to Mr. Takumi Shimogama for the outstanding help. This work was partly supported by Grants-in-Aid from the Japan Society for the promotion of Science to S.K. and Y.M.

\section{References}

1. Folkman J: Angiogenesis-dependent diseases. Semin Oncol 28: 536-542, 2001.

2. Carmeliet P: Angiogenesis in health and disease. Nat Med 9: 653-660, 2003.

3. Shojaei F, Zhong C, Wu X, Yu L and Ferrara N: Role of myeloid cells in tumor angiogenesis and growth. Trends Cell Biol 18: 372-378, 2008.

4. Ellis LM and Hicklin DJ: VEGF-targeted therapy: mechanisms of anti-tumour activity. Nat Rev Cancer 8: 579-591, 2008.

5. Ferrara N: Vascular endothelial growth factor: basic science and clinical progress. Endocr Rev 25: 581-611, 2004.

6. Shibuya M: Vascular endothelial growth factor-dependent and -independent regulation of angiogenesis. BMB Rep 41: 278-286, 2008 .

7. Bergers $G$ and Hanahan D: Modes of resistance to anti-angiogenic therapy. Nat Rev Cancer 8: 592-603, 2008.

8. Ellis LM and Hicklin DJ: Pathways mediating resistance to vascular endothelial growth factor-targeted therapy. Clin Cancer Res 14: 6371-6375, 2008.

9. Casanovas O, Hicklin DJ, Bergers G and Hanahan D: Drug resistance by evasion of antiangiogenic targeting of VEGF signaling in late-stage pancreatic islet tumors. Cancer Cell 8: 299-309, 2005

10. Wang Y and Becker D: Antisense targeting of basic fibroblast growth factor and fibroblast growth factor receptor-1 in human melanomas blocks intratumoral angiogenesis and tumor growth. Nat Med 3: 887-893, 1997.
11. Czubayko F, Liaudet-Coopman ED, Aigner A, Tuveson AT, Berchem GJ and Wellstein A: A secreted FGF-binding protein can serve as the angiogenic switch in human cancer. Nat Med 3: 1137-1140, 1997.

12. Compagni A, Wilgenbus $\mathrm{P}$, Impagnatiello MA, Cotton $\mathrm{M}$ and Christofori G: Fibroblast growth factors are required for efficient tumor angiogenesis. Cancer Res 60: 7163-7169, 2000.

13. Rousseau B, Larrieu-Lahargue F, Javaerzat S, Guihem-Ducleon F, Beermann F and Bikfalvi A: The tyrp1-Tag/tyrp1-FGFR1-DN bigenic mouse: a model for selective inhibition of tumor development, angiogenesis, and invasion into the neural tissue by blockade of fibroblast growth factor receptor activity. Cancer Res 64: 2490-2495, 2004.

14. Nissen LJ, Cao R, Hedlund EM, Wang Z, Zhao X, Wetterskog D, Funa K, Brakenhielm E and Cao Y: Angiogenic factors FGF2 and PDGF-BB synergistically promote murine tumor neo-vascularization and metastasis. J Clin Invest 117: 2766-2777, 2007.

15. Willett CG, Boucher Y, Duda DG, Di Tomaso E, Munn LL, Tong RT, Kozin SV, Petit L, Jain RK, Chung DC, Sahani DV, Kalva SP, Cohen KS, Scadden DT, Fischman AJ, Clark JW, Ryan DP, Zhu AX, Blaszkowsky LS, Shellito PC, MinoKenudson M and Lauwers GY: Surrogate markers for antiangiogenic therapy and dose-limiting toxicities for bevacizumab with radiation and chemotherapy: continued experience of a phase I trial in rectal cancer patients. J Clin Oncol 23: 8136-8139, 2005.

16. Oliner J, Min H, Leal J, Yu D, Rao S, You E, Tang X, Kim H, Meyer S, Han SJ, Hawkins N, Rosenfeld R, Davy E, Graham K, Jacobsen F, Stevenson S, Ho J, Chen Q, Hartmann T, Michaels M, Kelley M, Li L, Sitney K, Martin F, Sun JR, Zhang N, Lu J, Estrada J, Kumar R, Coxon A, Kaufman S, Pretorius J, Scully S, Cattley R, Payton M, Coats S, Nguyen L, Desilva B, Ndifor A, Hayward I, Radinsky R, Boone T and Kendall R: Suppresion of angiogenesis and tumor growth by selective inhibition of angiopoietin-2. Cancer Cell 6: 507-516, 2004.

17. Batchelor TT, Sorensen AG, Di Tomaso E, Zhang WT Duda DG, Cohen KS, Kozak KR, Cahill DP, Chen PJ, Zhu M, Ancukiewicz M, Mrugala MM, Plotkin S, Drappatz J, Louis DN, Ivy P, Scadden DT, Benner T, Loeffler JS, Wen PY and Jain RK: AZD2171, a pan-VEGF receptor tyrosine kinase inhibitor, normalizes tumor vasculature and alleviates edema in glioblastoma patients. Cancer Cell 11: 83-95, 2007.

18. Smithgall TE, Rogers JA, Peters KL, Li J, Briggs SD, Lionberger JM, Cheng H, Shibata A, Scholtz B, Schreiner S and Dunham N: The c-Fes family of protein-tyrosine kinases. Crit Rev Oncog 9: 43-62, 1998.

19. Greer P: Closing in on the biological functions of Fps/Fes and Fer. Nat Rev Mol Cell Biol 3: 278-289, 2002.

20. Kanda S, Miyata Y, Kanetake H and Smithgall TE: Non-receptor protein-tyrosine kinases as molecular targets for anti-angiogenic therapy. Int J Mol Med 20: 113-121, 2007.

21. Rogers JA, Read RD, Li J, Peters KL and Smithgall TE: Autophosphorylation of the Fes tyrosine kinase. Evidence for an intermolecular mechanism involving two kinase domain tyrosine residues. J Biol Chem 271: 17519-17525, 1996.

22. Read RD, Lionberger JM and Smithgall TE: Oligomerization of the Fes tyrosine kinase. Evidence for a coiled-coil domain in the unique N-terminal region. J Biol Chem 272: 18498-18503, 1997.

23. Cheng HY, Schiavone AP and Smithgall TE: A point mutation in the N-terminal coiled-coil domain releases c-Fes tyrosine kinase activity and survival signaling in myeloid leukemia cells. Mol Cell Biol 21: 6170-6180, 2001.

24. Kanda S, Lerner EC, Tsuda S, Shono T, Kanetake H and Smithgall TE: The non-receptor protein-tyrosine kinase c-Fes is involved in fibroblast growth factor-2-induced chemotaxis of murine brain capillary endothelial cells. J Biol Chem 275: 10105-10111, 2000.

25. Mochizuki Y, Nakamura T, Kanetake H and Kanda S: Angiopoietin 2 stimulates migration and tube-like structure formation of murine brain capillary endothelial cells through c-Fes and c-Fyn. J Cell Sci 115: 175-183, 2002.

26. Kanda S, Mochizuki Y and Kanetake H: Stromal cell-derived factor-1alpha induces tube-like structure formation of endothelial cells through phosphoinositide 3-kinase. J Biol Chem 278: 257-262, 2003.

27. Kanda S, Mochizuki Y, Miyata Y and Kanetake H: The role of c-Fes in vascular endothelial growth factor-A-mediated signaling by endothelial cells. Biochem Biophys Res Commun 306: 1056-1063, 2003. 
28. Berger W, Setinek U, Mohr T, Kindas-Mügge I, Vetterlein M, Dekan G, Eckersberger F, Caldas C and Micksche M: Evidence for a role of FGF-2 and FGF receptors in the proliferation of non-small cell lung cancer cells. Int J Cancer 83: 415-423, 1999.

29. Fischer H, Taylor N, Allerstorfer S, Grusch M, Sonvilla G, Holzmann K, Setinek U, Elbling L, Cantonati H, Grasl-Kraupp B, Gauglhofer C, Marian B, Micksche M and Berger W: Fibroblast growth factor receptor-mediated signals contribute to the malignant phenotype of non-small cell lung cancer cells: therapeutic implications and synergism with epidermal growth factor receptor inhibition. Mol Cancer Ther 7: 3408-3419, 2008.

30. Marek L, Ware KE, Fritzsche A, Hercule P, Helton WR, Smith JE, McDermott LA, Coldren CD, Nemenoff RA, Merrick DT, Helfrich BA, Bunn PA and Heasley LE: Fibroblast growth factor (FGF) and FGF receptor-mediated autocrine signaling in non-small cell lung cancer cells. Mol Pharmacol 75: 196-207, 2009.

31. Nishio, H, Nakamura, S, Horai, T, Ikegami, H and Matsuda M: Clinical and histopathologic evaluation of the expression of Ha-ras and fes oncogene products in lung cancer. Cancer 69: 1130-1136, 1992

32. Huang SM, Li J, Armstrong EA and Harari PM: Modulation of radiation response and tumor-induced angiogenesis after epidermal growth factor receptor inhibition by ZD1839 (Iressa). Cancer Res 62: 4300-4306, 2002.

33. Baselga J: Why the epidermal growth factor receptor? The rationale for cancer therapy. Oncologist 7 (Suppl. 4): 2-8, 2002.

34. Naba A, Reverdy C, Louvard D and Arpin M: Spatial recruitment and activation of the Fes kinase by ezrin promotes HGF-induced cell scattering. EMBO J 27: 38-50, 2008.

35. Wennström S, Landgren E, Blume-Jansen $P$ and ClaessonWelsh L: The platelet-derived growth factor-B-receptor kinase insert confers specific signaling properties to a chimeric fibroblast growth factor receptor. J Biol Chem 267: 13749-13756, 1992.

36. Nakamura T, Kanda S, Kohno T, Yamamoto K, Maeda K, Matsuyama T and Kanetake H: Increase in hepatocyte growth factor receptor tyrosine kinase activity in renal carcinoma cells is associated with increased motility through partly phosphoinositide 3-kinase. Oncogene 20: 7610-7623, 2001.

37. Wakeling AE, Guy SP, Woodburn JR, Ashton SE, Curry BJ, Barker AJ and Gibson KH: ZD1839 (Iressa): an orally active inhibitor of epidermal growth factor signaling with potential for cancer therapy. Cancer Res 62: 5749-5754, 2002.
38. Moasser MM, Basso A, Averbuch SD and Rosen N: The tyrosine kinase inhibitor ZD1839 (Iressa) inhibits HER2-driven signaling and suppresses the growth of HER2-overexpressing tumor cells. Cancer Res 61: 7184-7188, 2001.

39. Brehmer D, Greff Z, Godl K, Blencke S, Kurtenbach A, Weber M, Müller S, Klebl B, Cotten M, Kéri G, Wissing J and Daub H: Cellular targets of gefitinib. Cancer Res 62: 379-382, 2005.

40. Fabian MA, Biggs WH 3rd, Treiber DK, Atteridge CE, Azimioara MD, Benedetti MG, Carter TA, Ciceri P, Edeen PT, Floyd M, Ford JM, Galvin M, Gerlach JL, Grotzfeld RM, Herrgard S, Insko DE, Insko MA, Lai AG, Lélias JM, Mehta SA, Milanov ZV, Velasco AM, Wodicka LM, Patel HK, Zarrinkar PP and Lockhart DJ: A small molecule-kinase interaction map for clinical kinase inhibitors. Nat Biotechnol 23: 329-336, 2005.

41. Karaman MW, Herrgard S, Treiber DK, Gallant P, Atteridge CE, Campbell BT, Chan KW, Ciceri P, Davis MI, Edeen PT, Faraoni R, Floyd M, Hunt JP, Lockhart DJ, Milanov ZV, Morrison MJ, Pallares G, Patel HK, Pritchard S, Wodicka LM and Zarrinkar PP: A quantitative analysis of kinase inhibitor selectivity. Nat Biotechnol 26: 127-132, 2008.

42. Hjermstad SJ, Peters KL, Briggs SD, Glazer RI and Smithgall TE: Regulation of the human c-fes protein tyrosine kinase (p93c-fes) by its src homology 2 domain and major autophosphorylation site (Tyr-713). Oncogene 8: 2283-2292, 1993.

43. Filippakopoulos P, Kofler M, Hantschel O, Gish GD, Grebien F, Salah E, Neudecker P, Kay LE, Turk BE, Superti-Furga G, Pawson T and Knapp S: Structural coupling of SH2-kinase domains links Fes and Abl substrate recognition and kinase activation. Cell 134: 793-803, 2008.

44. Fruman DA, Meyers RE and Cantley LC: Phosphoinositide kinases. Annu Rev Biochem 67: 481-507, 1998.

45. Ranson M, Hammond LA, Ferry D, Kris M, Tullo A, Murray PI, Miller V, Averbuch S, Ochs J, Morris C, Feyereislova A, Swaisland H and Rowinsky EK: ZD1839, a selective oral epidermal growth factor receptor-tyrosine kinase inhibitor, is well tolerated and active in patients with solid, malignant tumors: results of a phase I trial. J Clin Oncol 20: 2240-2250, 2002. 